\title{
Suitability of the technical grape variety of the Northern Black Sea Coast in the traditional production for "Icewine"
}

\section{Victoriia Ostapenko, Natalia Kameneva}

\author{
Odesa National Academy of Food Technologies, Odesa, Ukraine
}

Keywords:
Icewine
Grape
Cluster
Composition
Black Sea

Article history:

Received

19.12.2017

Received in revised

form 28.12.2017

Accepted

29.12.2017

\section{Corresponding \\ author:}

Victoriia Ostapenko

E-mail:

ostapenkoviktoriya7

@gmail.com

DOI:

$10.24263 / 2304-$

974X-2017-6-4-12

\section{Abstract}

Introduction. The purpose of the work was to study the mechanical composition and physical and chemical properties of grape varieties in the Northern Black Sea Coast to determine their feasibility in icewine production.

Materials and methods. Riesling, Rkatsiteli and Telti Kuruk, Marselan and Moldova grape varieties for 2015-2018 in vineyards of Shabo, Tairov and Kherson were studied on the average mass of grape clusters, the number of berries in the cluster, the weight of grape berries, the weight of the grape peel, the mass of pulp with juice according to the technique prof. Prostoserdov.

Results and discussion. On average, the highest average weight of clusters in varieties of Moldova and Marselan was observed, the smallest - in Telti Kuruk and Riesling. After the advent of technological maturity, the mass of clusters in all varieties decreased from the end of October to the month of December: an average of 0.95 times in the Shabo region, 0.92 times in the Tairov region and 0.90 times in Kherson. The greatest differentiation in the number of berries during the warm months $\pm 4 \mathrm{p}$. and $\pm 6 \mathrm{p}$. had Rkatsiteli and Telti Kuruk, respectively, the smallest $- \pm 1 \mathrm{p}$. Moldova and Marselan in Shabo. On grape plantations in the village of Tairov and the city of Kherson, a significant difference in the number of berries by grade was not noted and was $\pm 1 \div \pm 3$ pcs.

Rkatsiteli accumulated the largest amount of sugar among other varieties, whose mass concentrations reached in December, on average by regions, from $243-245.13 \mathrm{~g} / \mathrm{dm}^{3}$, and the smallest ones were in Telti Kuruk, which amounted to $179.5-182.7 \mathrm{~g} / \mathrm{dm}^{3}$. In the Riesling variety after heavy rainfall, the mass concentration of sugars decreased to an average of $30 \mathrm{~g} / \mathrm{dm}^{3}$ - in the Shabo region, to $25 \mathrm{~g} / \mathrm{dm}^{3}$ - in the v. Tairov, and to $22 \mathrm{~g} / \mathrm{dm}^{3}-$ in the Kherson region. The mass fractions of sugars of Telti Kuruk were smaller and in November were $180-182.7 \mathrm{~g} / \mathrm{dm}^{3}$, than Riesling, which had mass concentrations in the end of October in the ranges of 199.5-201.6 g/dm ${ }^{3}$ during seasons of each year on vineyards of Shabo. The sugar accumulation of varieties during long-term maturing on the vine of the 3 regions during August-December of 2015-2018 were as follows: Rkatsiteli, Marselan, Moldova, Telti Kuruk, Riesling.

Conclusions. Riesling is not able to withstand a hard time on the vine after technological maturity, and the most suitable varieties were Marselan, Rkatsiteli and Moldova, which meet to the requirements that are needed for characteristic varieties for use in technology of icewines. 


\section{Introduction}

Icewine is one of the most unique among another types of wines. Unlike all others, it is made from frozen grapes, the berries are cooled directly on the vine. Water freezes, and sugar and other dissolved substances remain. Due to this particular grape must is concentrated and then it is very sweet. To make one liter, you need about $30 \mathrm{~kg}$ of berries. Icewine is a special dessert wine which has the certain requirements, among which the prominent place belongs to the agricultural climatic conditions: late maturing grape variety, the harvest of that occurs mainly in the winter months at air temperature $-7^{\circ} \mathrm{C}$.

Labor-intensive technology directly affects the release of wines, causing a high cost of goods and serves as the main reason for a limited comprehensive analysis of icewines. Today, Canada is the largest producer of icewine, but not the only one. It is also produced in Germany, Austria, Croatia, Luxembourg, Slovenia, Czech Republic, Hungary and the popularity of these unique wines is increasing every year [1].

Firstly, icewine was made from frozen Riesling. However, subsequent experiments allowed the selection of several more varieties of grapes. Austrians prefer Gruner Veltliner, Welschriesling and Gewürztraminer. Canadians use Vidal Blanc [2, 3, 12]. In the New World, icewine is produced from Merlot and Cabernet Sauvignon [2-11].

The availability of varieties to withstand adverse climatic conditions and the dynamics of their chemical composition for further use in technology of icewines in the scientific literature is almost absent. Only research on Canadian icewines is known from Riesling and Vidal Blanc, where the cool climate contributes to the larger size of the production of such wines [9-12].

The purpose of the work is to study the mechanical composition and physical and chemical properties of grape varieties in the Northern Black Sea Coast to determine their feasibility in the production of icewines.

\section{Materials and methods}

\section{Materials}

Experiments were carried out on white (Riesling, Rkatsiteli and Talti Kukur) and red (Marselan and Moldova) grape varieties. The research was conducted during 2015-2018 in vineyards of Shabo, Tairov and Kherson, part of the Northern Black Sea Coast. Conditions of experiment on the load of formation of bushes and age were regulated in the same range.

\section{Methods}

The mechanical composition, including the average mass of grape clusters $(\mathrm{g})$, the number of berries in the cluster (pieces), the weight of grape berries (g), the weight of the grape peel $(\mathrm{g})$, the weight of pulp with juice $(\mathrm{g})$ were determined according to the complex method for evaluating grapes that expresses the ratio of mechanical and plastic elements of bunches and berries [4], [5]. The $\mathrm{pH}$ was determined using the $\mathrm{pH}$ meter S220 (MettlerToledo International Inc., Switzerland), the concentration of titrated acids (TA) according to general method [6]. 


\section{Results and discussion}

\section{Mechanical composition of grape varieties}

The monitoring of the mechanical composition of grapes, which has undergone changes under the influence of meteorological factors and soil conditions in the area where the vine grows, makes it possible to state the techno-chemical quality of the grapes before the onset of low temperatures for the production of icewines. Parameters such as the average weight of grape bunch (g) (AWGB), the number of berries in the cluster (pcs) (NB), the weight of grape berries (g) (WB), the weight of the grape peel (g) (WP), the weight of pulp with juice (g) (WPJ), are mostly significant in the study of variety suitability in the production of sweet wines that can predict the following criteria: the output of must from frozen grapes (\%), the protection of berries by the skin from adverse conditions, the choice of the regime of pressing and processing, the direction of grape processing in general. The average and standard deviation of the mechanical composition of the grape cluster for 3 years of research during August-December 2015-2018 on the studied regions are given in Tables 1, 2.

Table 1

Indicators of mechanical composition of technical varieties of grapes in Shabo

\begin{tabular}{|c|c|c|c|c|c|c|}
\hline \multirow[t]{2}{*}{ Parameters } & \multirow{2}{*}{$\begin{array}{l}\tilde{E} \\
\sum\end{array}$} & \multicolumn{5}{|c|}{ Grape variety } \\
\hline & & Riesling & Rkatsiteli & Marselan & Moldova & Telti kuruk \\
\hline \multirow{5}{*}{ 1.AWGB (g) } & 08 & $84,7 \pm 2,08$ & $166,7 \pm 1,53$ & $194,7 \pm 0,58$ & $255,3 \pm 1,53$ & $109,3 \pm 0,58$ \\
\hline & 09 & $111,7 \pm 1,53$ & $169,7 \pm 1,15$ & $205,7 \pm 1,15$ & $267,7 \pm 1,15$ & $125,7 \pm 1,53$ \\
\hline & 10 & $97,3 \pm 4,16$ & $165,3 \pm 4,73$ & $212 \pm 2,65$ & $265,3 \pm 4,04$ & $120,7 \pm 3,06$ \\
\hline & 11 & & $162,7 \pm 4,04$ & $209 \pm 4,36$ & $264 \pm 4,0$ & $115,3 \pm 4,73$ \\
\hline & 12 & & $158,3 \pm 5,51$ & $203,3 \pm 4,04$ & $254,3 \pm 4,04$ & $104,7 \pm 3,51$ \\
\hline \multirow[t]{5}{*}{ 2. NB (pcs) } & 08 & $58 \pm 2$ & $90 \pm 2$ & $102 \pm 4$ & $146 \pm 1$ & $95 \pm 1$ \\
\hline & 09 & $70 \pm 2$ & $92 \pm 2$ & $109,0 \pm 2$ & $158 \pm 1$ & $101 \pm 3$ \\
\hline & 10 & $42 \pm 2$ & $88 \pm 4$ & $115 \pm 2$ & $154 \pm 1$ & $99 \pm 6$ \\
\hline & 11 & & $86 \pm 4$ & $109 \pm 8$ & $152 \pm 4$ & $9 \pm 5$ \\
\hline & 12 & & $83 \pm 4$ & $104 \pm 12$ & $146 \pm 6$ & $84 \pm 4$ \\
\hline \multirow[t]{5}{*}{ 3. WB (g) } & 08 & $79,4 \pm 2,2$ & $159,5 \pm 1,6$ & $187,0 \pm 1,0$ & $246,9 \pm 1,4$ & $103,1 \pm 0,7$ \\
\hline & 09 & $106,2 \pm 1,6$ & $162,5 \pm 1,1$ & $197,6 \pm 0,8$ & $258,9 \pm 1,1$ & $119,4 \pm 1,3$ \\
\hline & 10 & $62,0 \pm 4,2$ & $158,4 \pm 4,7$ & $204,0 \pm 3,0$ & $256,7 \pm 3,8$ & $114,8 \pm 3,0$ \\
\hline & 11 & & $155,8 \pm 4,0$ & $201,1 \pm 4,5$ & $255,6 \pm 3,9$ & $109,4 \pm 4,7$ \\
\hline & 12 & & $151,8 \pm 5,4$ & $195,9 \pm 4,0$ & $246,1 \pm 4,1$ & $98,8 \pm 3,4$ \\
\hline \multirow[t]{5}{*}{ 4. WP (g) } & 08 & $6,8 \pm 0,5$ & $6,8 \pm 0,5$ & $9,3 \pm 0,3$ & $9,2 \pm 0,2$ & $7,2 \pm 0,3$ \\
\hline & 09 & $7,3 \pm 0,3$ & $6,8 \pm 0,4$ & $9,4 \pm 0,3$ & $9,5 \pm 0,1$ & $7,7 \pm 0,2$ \\
\hline & 10 & $6,3 \pm 0,7$ & $6,9 \pm 0,5$ & $8,8 \pm 0,2$ & $9,0 \pm 0,2$ & $6,9 \pm 0,3$ \\
\hline & 11 & & $6,6 \pm 0,3$ & $8,3 \pm 0,2$ & $8,7 \pm 0,1$ & $6,4 \pm 0,2$ \\
\hline & 12 & & $6,1 \pm 0,3$ & $7,7 \pm 0,3$ & $8,1 \pm 0,6$ & $6,3 \pm 0,3$ \\
\hline \multirow[t]{5}{*}{ 5. WPJ (g) } & 08 & $71,7 \pm 2,9$ & $149,1 \pm 8,8$ & $169,4 \pm 7,5$ & $233,7 \pm 4,1$ & $94,6 \pm 0,2$ \\
\hline & 09 & $97,5 \pm 1,9$ & $151,7 \pm 3,2$ & $182,1 \pm 11,1$ & $243,4 \pm 6,6$ & $110,4 \pm 0,7$ \\
\hline & 10 & $83,9 \pm 3,5$ & $149,8 \pm 4,9$ & $193,9 \pm 3,6$ & $245,7 \pm 4,8$ & $106,6 \pm 3,4$ \\
\hline & 11 & & $146,9 \pm 4,7$ & $190,8 \pm 5,3$ & $244,6 \pm 4,5$ & $101,6 \pm 5,4$ \\
\hline & 12 & & $142,7 \pm 7,2$ & $184,8 \pm 3,1$ & $236,4 \pm 3,7$ & $87,8 \pm 7,2$ \\
\hline
\end{tabular}


According to its biological characteristics, the highest average mass of clusters among the varieties was observed in the varieties Moldova 265.3-277.7 $\mathrm{g}$ and Marselan 212-214 g, the smallest - in Telti Kuruk 104.7-109.3g and Riesling 80.0-84.7g, the Rkatsiteli variety was distinguished by the average masses of clusters compared to other 158.3$184.3 \mathrm{~g}$, regardless of region and month. After the advent of technological maturity, the mass of clusters in all varieties decreased from the end of October to December, on average 0.95 times in the Shabo region, 0.92 times - according to Tairov, 0.90 times - in Kherson.

Table 2

Indicators of mechanical composition of technical varieties of grapes in Tairov and Kherson

\begin{tabular}{|c|c|c|c|c|c|c|c|}
\hline \multirow[t]{3}{*}{ Parameters } & \multirow{3}{*}{ 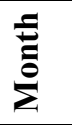 } & \multicolumn{6}{|c|}{ Grape variety } \\
\hline & & \multicolumn{2}{|c|}{ Riesling } & \multicolumn{2}{|c|}{ Rkatsiteli } & \multicolumn{2}{|c|}{ Moldova } \\
\hline & & Tairov & Kherson & Tairov & Kherson & Tairov & Kherson \\
\hline \multirow{5}{*}{ 1.AWGB (g) } & 08 & $81,7 \pm 0,6$ & $80,0 \pm 3,6$ & $175,3 \pm 1,5$ & $181,0 \pm 1,0$ & $268 \pm 1,0$ & $267,7 \pm 4,5$ \\
\hline & 09 & $110,3 \pm 1,5$ & $112,0 \pm 2,6$ & $171 \pm 2,6$ & $184,3 \pm 0,6$ & $276,3 \pm 1,5$ & $277,7 \pm 1,5$ \\
\hline & 10 & $94,7 \pm 0,6$ & $101,7 \pm 11,8$ & $169 \pm 3,0$ & $176,3 \pm 1,5$ & $271,7 \pm 2,1$ & $272,0 \pm 2,6$ \\
\hline & 11 & & & $165,3 \pm 4,2$ & $169,3 \pm 1,2$ & $268 \pm 2,6$ & $267,7 \pm 2,5$ \\
\hline & 12 & & & $157,7 \pm 3,8$ & $159,3 \pm 1,2$ & $259,7 \pm 5,5$ & $259,3 \pm 4,5$ \\
\hline \multirow[t]{5}{*}{ 2. NB (pcs) } & 08 & $60 \pm 2$ & $59 \pm 5$ & $96 \pm 3$ & $108 \pm 3$ & $149 \pm 1$ & $156 \pm 3$ \\
\hline & 09 & $67 \pm 2$ & $62 \pm 3$ & $92 \pm 2$ & $111 \pm 2$ & $166 \pm 3$ & $166 \pm 1$ \\
\hline & 10 & $41 \pm 2$ & $48 \pm 3$ & $88 \pm 3$ & $103 \pm 1$ & $162 \pm 3$ & $161 \pm 1$ \\
\hline & 11 & & & $86 \pm 2$ & $96 \pm 2$ & $157 \pm 2$ & $156 \pm 2$ \\
\hline & 12 & & & $80 \pm 2$ & $87 \pm 2$ & $148 \pm 1$ & $147 \pm 2$ \\
\hline \multirow[t]{5}{*}{ 3. WB (g) } & 08 & $76,4 \pm 0,5$ & $74,8 \pm 3,4$ & $168,2 \pm 1,5$ & $173,9 \pm 1,0$ & $259,5 \pm 1,1$ & $259,2 \pm 4,5$ \\
\hline & 09 & $104,9 \pm 1,5$ & $106,5 \pm 2,6$ & $163,8 \pm 2,6$ & $177,2 \pm 0,7$ & $267,6 \pm 1,7$ & $268,9 \pm 1,7$ \\
\hline & 10 & $59,4 \pm 0,6$ & $66,4 \pm 11,8$ & $162,0 \pm 3,0$ & $169,4 \pm 1,6$ & $263,0 \pm 2,3$ & $263,3 \pm 2,9$ \\
\hline & 11 & & & $158,5 \pm 4,2$ & $162,5 \pm 1,2$ & $259,6 \pm 2,8$ & $259,3 \pm 2,6$ \\
\hline & 12 & & & $151,1 \pm 3,8$ & $152,8 \pm 3,7$ & $251,5 \pm 5,6$ & $251,1 \pm 4,6$ \\
\hline \multirow[t]{5}{*}{ 4. WP (g) } & 08 & $7,1 \pm 0,1$ & $6,9 \pm 0,1$ & $7,4 \pm 0,1$ & $7,2 \pm 0,1$ & $9,6 \pm 0,2$ & $9,3 \pm 0,2$ \\
\hline & 09 & $7,4 \pm 0,3$ & $7,2 \pm 0,1$ & $7,4 \pm 0,1$ & $7,3 \pm 0,1$ & $9,8 \pm 0,2$ & $9,5 \pm 0,1$ \\
\hline & 10 & $6,8 \pm 0,4$ & $7,1 \pm 0,1$ & $7,0 \pm 0,3$ & $7,1 \pm 0,1$ & $9,6 \pm 0,1$ & $9,6 \pm 0,1$ \\
\hline & 11 & & & $6,6 \pm 0,1$ & $6,8 \pm 0,1$ & $9,1 \pm 0,1$ & $9,3 \pm 0,1$ \\
\hline & 12 & & & $6,1 \pm 0,1$ & $6,4 \pm 0,3$ & $8,7 \pm 0,2$ & $8,8 \pm 0,1$ \\
\hline \multirow[t]{5}{*}{ 5. WPJ (g) } & 08 & $69,3 \pm 0,5$ & $67,9 \pm 3,3$ & $160,8 \pm 1,4$ & $166,6 \pm 0,9$ & $249,9 \pm 1,0$ & $249,9 \pm 4,4$ \\
\hline & 09 & $97,5 \pm 1,6$ & $99,3 \pm 2,6$ & $156,4 \pm 2,6$ & $169,8 \pm 0,8$ & $257,8 \pm 1,8$ & $259,4 \pm 1,6$ \\
\hline & 10 & $82,6 \pm 0,4$ & $89,3 \pm 11,8$ & $155,0 \pm 2,7$ & $162,3 \pm 1,6$ & $253,4 \pm 2,3$ & $253,7 \pm 2,8$ \\
\hline & 11 & & & $151,9 \pm 4,2$ & $155,7 \pm 1,3$ & $250,6 \pm 2,8$ & $250,0 \pm 2,5$ \\
\hline & 12 & & & $145,0 \pm 3,8$ & $146,4 \pm 3,9$ & $242,8 \pm 5,6$ & $242,4 \pm 4,6$ \\
\hline
\end{tabular}

The general reflection of the influence of precipitation on the mechanical structure of the cluster is found in the mass of grape berries, which depended directly on the number of berries. Thus, the greatest differentiation in the number of berries during the warm months of the autumn \pm 4 and \pm 6 ps had varieties of Rkatsiteli and Telti Kuruk respectively, the smallest - \pm 1 p Moldova and Marselan in vineyards of Shabo. On grape plantations in the village of Tairov and the city of Kherson, a significant difference in the number of berries 
by cultivars was not noted and was $\pm 1 \div \pm 3$ pcs. However, in November and December all varieties of these regions were characterized by a sharp decrease in the number of berries in the cluster, which was reflected directly in the lower mass of the cluster, which is due to overgrowing and the possible effect of the precipitation. Thus, the Rkatsiteli variety at the technological maturity of the berries in the cluster was 92 pcs in the Shabo and Tairov region and $103 \mathrm{~g}$ in Kherson, the weight of which was $162.5,163.8$ and $177.2 \mathrm{~g}$, after the cold months $-83,80$ and 87 pcs with the corresponding weight of $151.8,151.1 \mathrm{~g}$ and 152.8 $\mathrm{g}$. The weight of berries in Moldova variety decreased from 258.9-263.3 g to $246.1-$ $251.1 \mathrm{~g}$ with the number of berries $166-146 \mathrm{pcs}$ to $147-148 \mathrm{pcs}$, respectively, on average over the years. Marselan and Telti Kuruk were characterized by the amount of berries in the cluster of 115 and 101 pcs with a weight of 204 and $119.4 \mathrm{~g}$, and after prolonged stay on the vine, the number of berries was 104 and 84 pcs with a weight of 195.9 and $98.8 \mathrm{~g}$. However, from September to October, the Riesling variety lost 28, 26 and 24 berries, the weight of which decreased by $44.2,45.5$ and $40 \mathrm{~g}$, according to the regions of growing Shabo, Tairov and Kherson.

Also, it should be noted that the direct dependence of the influence of precipitation on the mechanical composition of the cluster reflects the stability of a certain variety of grapes to diseases and the effects of pests.

The largest weight of the skin was noted in red grape varieties $-9.0 \pm 0.7 \mathrm{~g}$ and $8.8 \pm 0.5$ $\mathrm{g}$ in Moldova in all regions and Marselan respectively. The white varieties were characterized by the average weight of the skin, which varied from 6.0 to $7.3 \mathrm{~g}$ in Riesling, from 6.1 to $7.4 \mathrm{~g}$ in Rkatsiteli, from 6.3 to $7.7 \mathrm{~g}$ in Telti Kuruk. With the continuation of the harvest period, the weight of the skin of the studied grape varieties became thinner, which made their weight lighter, on average, $0.3,0.96,1.25,1.7$ and $1.4 \mathrm{~g}$ respectively, according to Riesling, Rkatsiteli, Moldova, Marselan and Telti Kuruk, and therefore more vulnerable to adverse climatic factors.

Despite the fact that the rainy season recorded for September-October of all three years, the parameters of the mechanical composition of grape varieties, Moldova and Marselan, did not change critically at the location of the first frosts compared with other varieties, indicating the probable first feasibility of using these varieties in icewine technology.

The conditionality of the studied varieties according to the statistic results of the cluster's mechanical composition during August-January 2015-2018 in the three regions is shown in this order Moldova, Marselan, Rkatsiteli, Telti Kuruk, Riesling (from the highest to the smallest).

\section{Chemical indicators of grape quality}

One of the most important factors of the suitability of a variety for the icewine production is the rapid accumulation of the sugar content of frozen berries and their initial concentration to freezing to determine the stages of maturation and oversaturation of this indicator.

The dynamics of the physicochemical properties of the grapes studied by the varieties shows that varieties accumulate sugar differently depending on the time and region of cultivation (Table 3.1-3.3) 
Dynamics of physical and chemical properties of grapes from Shabo

Table 3.1

\begin{tabular}{|c|c|c|c|c|c|c|}
\hline Parameters & Month & Riesling & Rkatsiteli & Marselan & Moldova & Telti Kuruk \\
\hline \multirow{4}{*}{$\begin{array}{c}\text { Mass concentration } \\
\text { of sugars, g/dm }\end{array}$} & 08 & $143,53 \pm 9,5$ & $180,67 \pm 5,5$ & $195,37 \pm 4,7$ & $187,77 \pm 0,9$ & $137,63 \pm 1,8$ \\
\cline { 2 - 7 } & 09 & $199,50 \pm 7,1$ & $185,73 \pm 9,2$ & $197,53 \pm 1,6$ & $195,27 \pm 0,6$ & $140,20 \pm 1,06$ \\
\cline { 2 - 7 } & 10 & $171,5 \pm 13$ & $192,10 \pm 10,25$ & $223,80 \pm 3,1$ & $220,97 \pm 1,7$ & $160,30 \pm 1,2$ \\
\cline { 2 - 7 } & 11 & & $223,00 \pm 4,9$ & $217,83 \pm 5,6$ & $219,57 \pm 0,9$ & $170,13 \pm 2,7$ \\
\cline { 2 - 7 } & 12 & & $243,07 \pm 4,27$ & $237,77 \pm 1,1$ & $236,60 \pm 1,1$ & $181,00 \pm 1,7$ \\
\hline \multirow{4}{*}{$\begin{array}{c}\text { Mass concentration } \\
\text { of titrated acids, g/dm }\end{array}$} & 08 & $8,47 \pm 0,25$ & $7,70 \pm 0,1$ & $8,20 \pm 0,06$ & $8,07 \pm 0,1$ & $9,00 \pm 0,17$ \\
\cline { 2 - 7 } & 09 & $7,83 \pm 0,21$ & $6,90 \pm 0,1$ & $7,13 \pm 0,12$ & $7,57 \pm 0,2$ & $8,57 \pm 0,12$ \\
\cline { 2 - 7 } & 10 & $6,70 \pm 0,17$ & $6,50 \pm 0,26$ & $6,27 \pm 0,12$ & $6,77 \pm 0,15$ & $7,00 \pm 0,10$ \\
\cline { 2 - 7 } & 11 & & $6,10 \pm 0,26$ & $5,80 \pm 0,15$ & $6,23 \pm 0,15$ & $6,53 \pm 0,15$ \\
\hline \multirow{5}{*}{$\mathrm{pH}$} & 08 & $2,69 \pm 0,02$ & $2,88 \pm 0,01$ & $2,91 \pm 0,01$ & $2,94 \pm 0,02$ & $2,82 \pm 0,01$ \\
\cline { 2 - 7 } & 09 & $2,71 \pm 0,03$ & $2,96 \pm 0,02$ & $2,97 \pm 0,02$ & $3,12 \pm 0,01$ & $2,89 \pm 0,02$ \\
\cline { 2 - 7 } & 10 & $3,04 \pm 0,02$ & $2,99 \pm 0,02$ & $3,02 \pm 0,01$ & $3,21 \pm 0,01$ & $3,01 \pm 0,03$ \\
\cline { 2 - 7 } & 11 & & $3,07 \pm 0,02$ & $3,10 \pm 0,02$ & $3,24 \pm 0,02$ & $3,12 \pm 0,01$ \\
\cline { 2 - 7 } & 12 & & $3,14 \pm 0,01$ & $3,14 \pm 0,02$ & $3,27 \pm 0,01$ & $3,14 \pm 0,01$ \\
\hline
\end{tabular}

Table 3.2

Dynamics of physical and chemical properties of grapes from Tairov

\begin{tabular}{|c|c|c|c|c|}
\hline Parameters & Month & Riesling & Rkatsiteli & Moldova \\
\hline \multirow{4}{*}{$\begin{array}{c}\text { Mass concentration } \\
\text { of sugars, g/dm }\end{array}$} & 08 & $144,63 \pm 9,6$ & $180,7 \pm 5,7$ & $188,8 \pm 1,4$ \\
\cline { 2 - 5 } & 09 & $200,6 \pm 7,4$ & $186,3 \pm 9,4$ & $196,2 \pm 1,6$ \\
\cline { 2 - 5 } & 10 & $172,66 \pm 13$ & $193,2 \pm 10,3$ & $221,9 \pm 1,7$ \\
\cline { 2 - 5 } & 11 & & $224,0 \pm 5,1$ & $220,3 \pm 0,5$ \\
\cline { 2 - 5 } & 12 & & $244,0 \pm 4,1$ & $237,5 \pm 1,5$ \\
\hline \multirow{4}{*}{\begin{tabular}{c} 
Mass concentration $\begin{array}{c}\text { of } \\
\text { titrated acids, } \\
\text { g/dm }\end{array}$ \\
\cline { 2 - 5 }
\end{tabular}} & 08 & $8,36 \pm 0,32$ & $7,63 \pm 0,1$ & $7,9 \pm 0,14$ \\
\cline { 2 - 5 } & 09 & $7,73 \pm 0,3$ & $6,8 \pm 0,2$ & $7,4 \pm 0,13$ \\
\cline { 2 - 5 } & 10 & $6,6 \pm 0,18$ & $6,43 \pm 0,24$ & $6,6 \pm 0,15$ \\
\cline { 2 - 5 } & 11 & & $6,03 \pm 0,23$ & $6,1 \pm 0,12$ \\
\hline \multirow{4}{*}{$\mathrm{pH}$} & 08 & $2,72 \pm 0,1$ & $2,85 \pm 0,01$ & $2,87 \pm 0,01$ \\
\cline { 2 - 5 } & 09 & $2,74 \pm 0,01$ & $2,94 \pm 0,02$ & $3,05 \pm 0,02$ \\
\cline { 2 - 5 } & 10 & $3,07 \pm 0,02$ & $2,95 \pm 0,01$ & $3,14 \pm 0,02$ \\
\cline { 2 - 5 } & 11 & & $3,08 \pm 0,02$ & $3,17 \pm 0,01$ \\
\cline { 2 - 5 } & 12 & & $3,15 \pm 0,01$ & $3,2 \pm 0,02$ \\
\hline
\end{tabular}


Dynamics of physical and chemical properties of grapes from Kherson

\begin{tabular}{|c|c|c|c|c|}
\multirow{4}{*}{ Parameters } & Month & Riesling & Rkatsiteli & Moldova \\
\cline { 2 - 5 } & 08 & $145,7 \pm 9,78$ & $181,7 \pm 6,4$ & $189,5 \pm 1,9$ \\
\cline { 2 - 5 } $\begin{array}{c}\text { Mass concentration } \\
\text { of sugars, g/dm }\end{array}$ & 09 & $201,6 \pm 8,3$ & $187,7 \pm 10,2$ & $197,3 \pm 1,6$ \\
\cline { 2 - 5 } & 10 & $173,3 \pm 14$ & $194,2 \pm 10,8$ & $222,9 \pm 1,5$ \\
\cline { 2 - 5 } & 11 & & $225,4 \pm 5,7$ & $211,3 \pm 1,02$ \\
\cline { 2 - 5 } & 12 & & $245,3 \pm 4,05$ & $238,4 \pm 1,9$ \\
\hline \multirow{4}{*}{$\begin{array}{c}\text { Mass concentration } \\
\text { of titrated acids, } \\
\text { g/dm }\end{array}$} & 08 & $8,5 \pm 0,4$ & $7,8 \pm 0,15$ & $8,2 \pm 0,1$ \\
\cline { 2 - 5 } & 09 & $7,9 \pm 0,2$ & $7,03 \pm 0,11$ & $7,7 \pm 0,17$ \\
\cline { 2 - 5 } & 10 & $6,8 \pm 0,1$ & $6,6 \pm 0,25$ & $6,9 \pm 0,1$ \\
\cline { 2 - 5 } & 11 & & $6,3 \pm 0,21$ & $6,3 \pm 0,15$ \\
\cline { 2 - 5 } & 12 & & $5,7 \pm 0,21$ & $5,7 \pm 0,13$ \\
\hline \multirow{4}{*}{$\mathrm{pH}$} & 08 & $2,73 \pm 0,02$ & $2,86 \pm 0,02$ & $2,92 \pm 0,02$ \\
\cline { 2 - 5 } & 09 & $2,75 \pm 0,03$ & $2,94 \pm 0,01$ & $3,13 \pm 0,02$ \\
\cline { 2 - 5 } & 10 & $3,05 \pm 0,02$ & $2,96 \pm 0,01$ & $3,2 \pm 0,02$ \\
\cline { 2 - 5 } & 11 & & $3,1 \pm 0,02$ & $3,24 \pm 0,01$ \\
\cline { 2 - 5 } & 12 & & $3,17 \pm 0,01$ & $3,25 \pm 0,01$ \\
\hline
\end{tabular}

The highest concentration of sugars was observed in all studied varieties at the end of November: in Riesling 199.5, 200.6, $201.6 \mathrm{~g} / \mathrm{dm}^{3}$; Rkatsiteli 243.7, 244, $245.3 \mathrm{~g} / \mathrm{dm}^{3}$; in Moldova 236.6, 237.5, $238.4 \mathrm{~g} / \mathrm{dm}^{3}$; Marselan $237.7 \mathrm{~g} / \mathrm{dm}^{3}$ and Telti Kuruk $181 \mathrm{~g} / \mathrm{dm}^{3}$ in accordance with the regions of Shabo, Tairov and Kherson. In the red varieties of grapes, the rate of accumulation of sugar was slower, an average of 3-5 marks less during the months of October-November compared with white, but the mass concentration of sugar content was significantly higher, which is due to the late degree of berry maturation (Table 3.1-3.3).

Order of the grape varieties studied according to the accumulation of sugar during long maturation on the vine of the three regions during August-December 2015-2018 are Rkatsiteli, Marselan, Moldova, Telti Kuruk, Riesling.

Detailed monitoring of temperatures in December-January 2015-2018 in all regions made it possible to determine the grape harvesting time, which was frozen on the vine, which occurred in the early hours of the morning and made the complexity of the technological process to maintain the desired concentration of sugars - above $280 \mathrm{~g} / \mathrm{dm}^{3}$. It is precisely the achievement of the grapes of the specified condition that makes it possible to direct it to the production of icewines. Riesling has not shown tendency to long-term preservation of technological parameters on the vine during three seasons in three regions. The dynamics of the concentration of sugars in the studied varieties was not the same (Figures 1-3). 

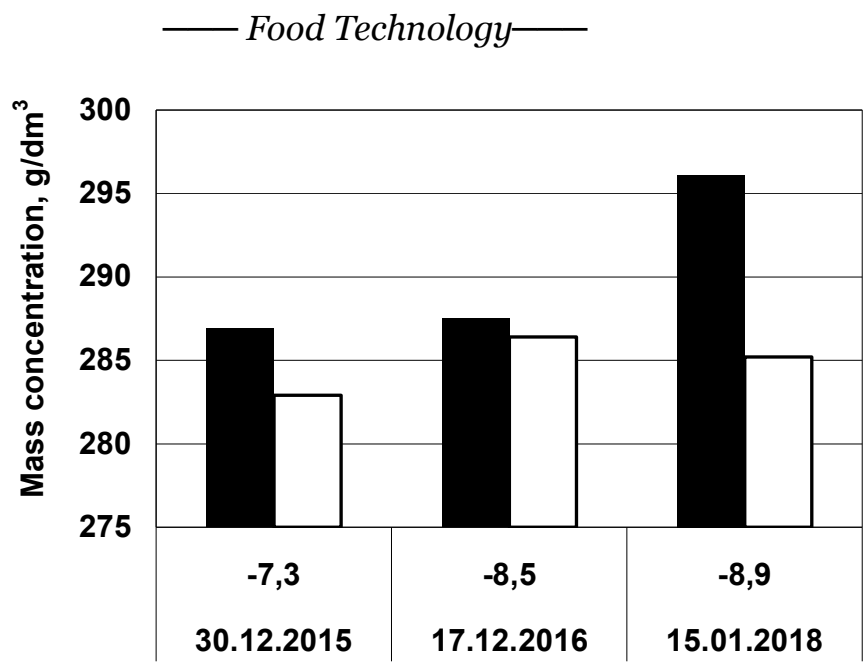

Rkatsiteli $\quad \square$ Moldova

Figure 1. Dynamics of sugar concentration of varieties of Rkatsiteli and Moldova depending on the date and minus temperature in Tairov (2015-2018)

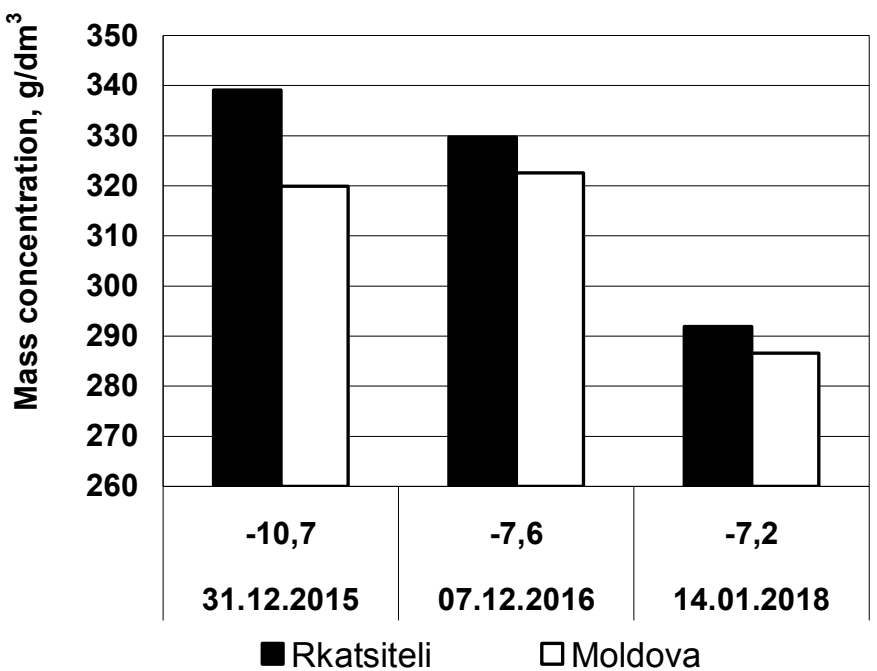

Figure 2. Dynamics of sugar concentration of varieties of Rkatsiteli and Moldova depending on the date and minus temperature in Kherson (2015-2018) 


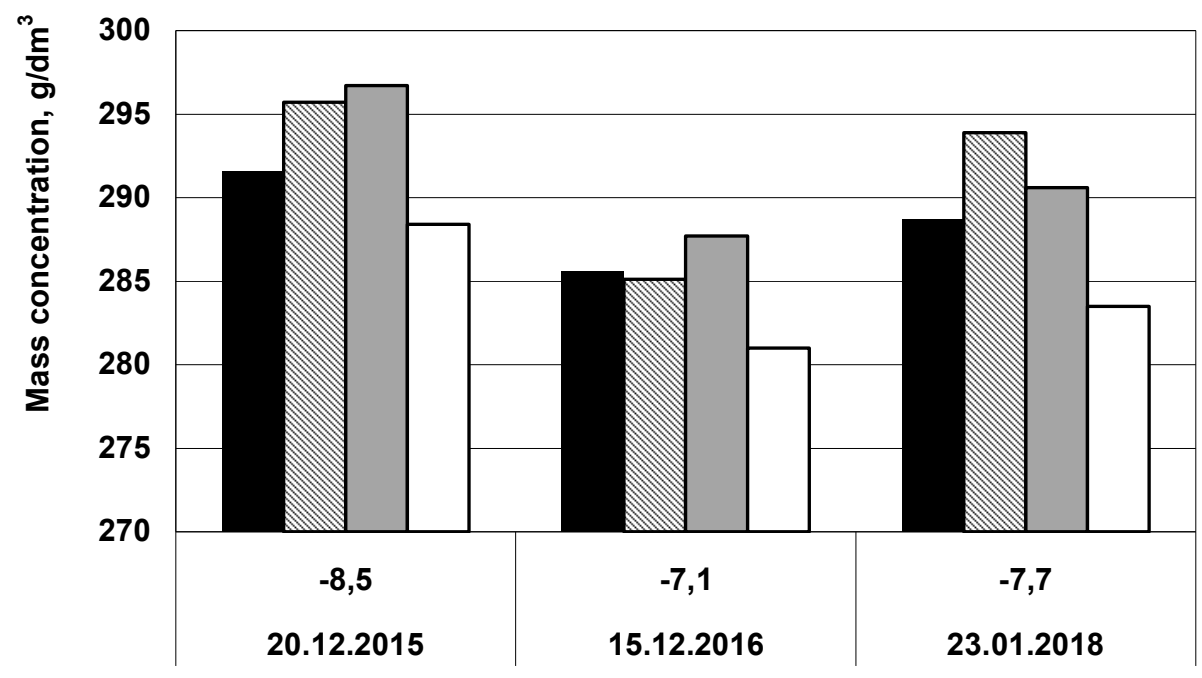

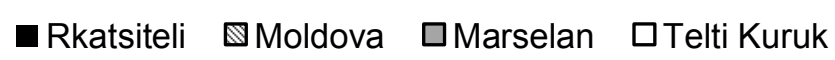

Figure 3. Dynamics of concentration of sugar of grape varieties, depending on the date and minus temperature in $\mathrm{v}$. Shabo (2015-2018)

In December 2016, in the Tairov region, Rkatsiteli and Moldova had a mass concentration of sugar 287.5 and $286.4 \mathrm{~g} / \mathrm{dm}^{3}$, which is 4.1 and $9.3 \mathrm{~g} / \mathrm{dm}^{3}$ less than in 2015 in Shabo, although the grape harvest was carried out at the same temperature $-8.5^{\circ} \mathrm{C}$. At $7.6{ }^{\circ} \mathrm{C}$ in 2016 and $-7.2{ }^{\circ} \mathrm{C}$ in 2018 , the Rkatsiteli variety, frozen in the vineyards of Kherson, showed a higher sugar content compared with the crop collected from the v. Shabo a week later of the same years by 13.5 and $11.6 \%$ and with a temperature difference of 0.6 and $0.5{ }^{\circ} \mathrm{C}$ respectively. The lower the temperature, the higher the accumulation of sugar was observed in the Moldova variety, however, in Kherson was the highest mass concentration of $322.6 \mathrm{~g} / \mathrm{dm}^{3}$ in 2016 when the thermometer was marked $-7.6{ }^{\circ} \mathrm{C}$, when $10^{\circ} \mathrm{C}$, in 2015 , and sugar content was lower $-319.9 \mathrm{~g} / \mathrm{dm}^{3}$.

Another red variety, Marselan, contained higher sugar in berries frozen on a vine compared to Moldova, but no significant difference was noted: 1 and $2.6 \mathrm{~g} / \mathrm{dm}^{3}$ more than 2016-2017 years of harvest. The native grape variety Telti Kuruk showed the lowest accumulation of mass concentrations of sugar among the studied varieties, which, on average, amounted to $284.3 \mathrm{~g} / \mathrm{dm}^{3}$ by years.

The concentration of titrated acids and $\mathrm{pH}$ values show a tendency with lower temperatures, higher $\mathrm{pH}$ values $(\mathrm{p} \leq 0.01, \mathrm{p} \leq 0.001)$, and the mass concentrations of titrated acids did not differ significantly among all grape varieties $(\mathrm{p} \leq 0.05, \mathrm{n} / \mathrm{s})$. This fact is explained by the distribution of constituent substances in the grape during prolonged maturation, where sugar concentrates more and the acid content decreases, therefore, even at low temperatures, slight increases in the parameters of this parameter are observed. Thus, the mass concentration of titrated acids of the Rkatsiteli variety was the same and amounted to $8.9 \mathrm{~g} / \mathrm{dm}^{3}$ at temperatures of $-7.1,-7.3,-8.9,-10.7^{\circ} \mathrm{C}$ in different regions, and the $\mathrm{pH}$ values increased with decreasing temperatures. According to the mathematical treatment, a similar situation was also observed in the Marselan variety, where the content of titrated 
acidity was found in the amount of 9.1-9.2 $\mathrm{g} / \mathrm{dm}^{3}$, and the active acidity had a growing direction, varying in the range of 3,583,78. In Shabo region, the varieties of Moldova and Telti Kuruk did not differ in terms of the values of the analyzed chemical parameters from the collection dates of $9.2 \mathrm{~g} / \mathrm{dm}^{3}$ and $\mathrm{pH} 3.67$ and $8.6 \mathrm{~g} / \mathrm{dm}^{3}$ at $\mathrm{pH} 3,58$, respectively, in each year (Table 4).

Statistic analysis has made it possible to conclude that it is precisely the stability of grapes to diseases and pests and biological peculiarities of grapes that significantly affect the chemical properties of grape varieties under consideration in traditional freezing.

Mass concentration of titrated acids and $\mathrm{pH}$ of grapes, 2015-2018

Table 4

\begin{tabular}{|c|c|c|c|c|c|c|c|c|c|}
\hline \multirow{2}{*}{ Harvest } & \multirow{2}{*}{$\mathbf{T},{ }^{\circ} \mathbf{C}$} & \multicolumn{2}{|c|}{ Rkatsiteli } & \multicolumn{2}{|c|}{ Moldova } & \multicolumn{2}{|c|}{ Marselan } & \multicolumn{2}{|c|}{ Telti Kuruk } \\
\hline & & TA & pH & TA & pH & TA & pH & TA & pH \\
\hline \multicolumn{10}{|c|}{ Tairov } \\
\hline 30.12 .2015 & $-7,3$ & $8,9^{\mathrm{a}}$ & $3,62^{b}$ & $8,7^{\mathrm{a}}$ & $3,48^{\mathrm{a}}$ & & & & \\
\hline 17.12 .2016 & $-8,5$ & $8,7^{\mathrm{a}}$ & $3,57^{\mathrm{a}}$ & $9^{b}$ & $3,52^{b}$ & & & & \\
\hline 15.01 .2018 & $-8,9$ & $8,9^{\mathrm{a}}$ & $3,76^{\mathrm{c}}$ & $9,2^{b}$ & $3,74^{\mathrm{c}}$ & & & & \\
\hline p-value & & $\mathrm{n} / \mathrm{s}$ & 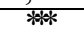 & 将 & 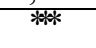 & & & & \\
\hline \multicolumn{10}{|c|}{ Kherson } \\
\hline 31.12 .2015 & $-10,7$ & $8,9^{\mathrm{a}}$ & $3,73^{\mathrm{c}}$ & $9,2^{\mathrm{a}}$ & $3,67^{\mathrm{c}}$ & & & & \\
\hline 07.12 .2016 & $-7,6$ & $9^{b}$ & $3,66^{b}$ & $9,3^{\mathrm{a}}$ & $3,54^{b}$ & & & & \\
\hline 14.01 .2018 & $-7,2$ & $9,1^{b}$ & $3,62^{\mathrm{a}}$ & $9,3^{\mathrm{a}}$ & $3,45^{\mathrm{a}}$ & & & & \\
\hline p-value & & & 栦 & $\mathrm{n} / \mathrm{s}$ & & & & & \\
\hline \multicolumn{10}{|c|}{ Shabo } \\
\hline 20.12 .2015 & $-8,5$ & $8,9^{\mathrm{a}}$ & $3,62^{\mathrm{b}}$ & $9,2^{\mathrm{a}}$ & $3,66^{\mathrm{a}}$ & $9,1^{\mathrm{a}}$ & $3,78^{\mathrm{c}}$ & $8,5^{\mathrm{a}}$ & $3,56^{\mathrm{a}}$ \\
\hline 15.12 .2016 & $-7,1$ & $8,8^{\mathrm{a}}$ & $3,57^{\mathrm{a}}$ & $9,2^{\mathrm{a}}$ & $3,67^{\mathrm{a}}$ & $9,2^{\mathrm{a}}$ & $3,58^{\mathrm{a}}$ & $8,6^{\mathrm{a}}$ & $3,58^{\mathrm{a}}$ \\
\hline 23.01 .2018 & $-7,7$ & $8,8^{\mathrm{a}}$ & $3,61^{b}$ & $9,3^{\mathrm{a}}$ & $3,67^{\mathrm{a}}$ & $9,1^{\mathrm{a}}$ & $3,63^{b}$ & $8,6^{\mathrm{a}}$ & $3,58^{\mathrm{a}}$ \\
\hline p-value & & $\mathrm{n} / \mathrm{s}$ & * & $\mathrm{n} / \mathrm{s}$ & $\mathrm{n} / \mathrm{s}$ & $\mathrm{n} / \mathrm{s}$ & 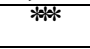 & $\mathrm{n} / \mathrm{s}$ & $\mathrm{n} / \mathrm{s}$ \\
\hline
\end{tabular}

Note: ${ }^{*}{ }^{*}$, $^{*}{ }^{*}$ - significance at $\mathrm{p} \leq 0.05,0.01$ and 0.001 respectively; $\mathrm{n} / \mathrm{s}$ value is not significant. Values for columns with the same letter do not differ significantly.

\section{Conclusions}

The peculiarities of the change in the quality of the mechanical composition of grapes, revealed during long maturation, made it possible to highlight the suitability of a particular variety to withstand adverse climatic conditions in a particular area, which is one of the key details for the production of icewines. The mass concentrations of titrated acids of all grapes after the onset of technological maturity had a direction to decrease, and the $\mathrm{pH}$ increased.

On the basis of the data presented, it can be stated that Riesling, in accordance with the climatic conditions of the Northern Black Sea Region, is not able to withstand a hard time on the vine after technological maturity, and therefore is not a perspective cultivar for the production of icewines in Ukraine. The most suitable varieties were Marselan, Rkatsiteli and Moldova, which according to their physicochemical parameters and mechanical composition meet the requirements that are needed for the characteristic varieties for use in technology of icewines. 


\section{References}

1. Ostapenko V., Tkachenko O., I.E. (2016), Analysis of market current state and historical roots of ice wine production, Technology audit and production reserves, 5(31), pp. 46-53.

2. Nurgel, C., Pickering, G.J. \& Inglis, D.L. (2004), Sensory and chemical characteristics of Canadian ice wines, Journal of the Science of Food and Agriculture, 84(13), pp. $1675-1684$.

3. Rivard D. (2016), Challenges and Solutions for Icewine and Cryo Wine Production.

4. Prostoserdov N.N. (1963), Izuchenie vinograda dlia opredeleniia ego ispolzovaniia, Pishchepromizdat, p. 77.

5. Delic Mersija, Kolic Agan, Behmen Fikreta, Dimovska Violeta, Matijasevic Sasa, Rankovic-Vasic Zorica (2015), Effect of bud loads on mechanical composition of cluster and chemical content of must in Victoria table grape variety (Vitis Vinifera L.), 25th International scientific experts congres on agriculture and food industry, Turkey 2014, pp. 269-272.

6. Erasmus D.J., Cliff M., Van Vuuren H.J.J. (2004), Impact of yeast strain on the production of acetic acid, glycerol, and the sensory attributes of icewine, American Journal of Enology and Viticulture, 55(4), pp. 371-378.

7. Bowen A.J., Reynolds A.G. (2012), Odor potency of aroma compounds in Riesling and Vidal blanc table wines and icewines by gas chromatography-olfactometry-mass spectrometry, Journal of Agricultural and Food Chemistry, 60(11), pp. 2874-2883.

8. González-álvarez M. et al. (2014), Sensory description of sweet wines obtained by the winemaking procedures of raisining, botrytisation and fortification, Food Chemistry, 145, pp. 1021-1030.

9. Synos K., Reynolds A.G. \& Bowen A.J. (2015), Effect of yeast strain on aroma compounds in Cabernet franc icewines, LWT - Food Science and Technology, 64(1), pp. 227-235.

10. Liu L. et al. (2008), Preliminary study on the application of visible-near infrared spectroscopy and chemometrics to classify Riesling wines from different countries, Food Chemistry, 106(2), pp. 781-786.

11. Ostapenko V. (2016), Analysis on application of different grape varieties in the production of icewine. A review, Ukrainian Food Journal, 5(4), pp.678-694.

12. Montaigne Etienne, Coelho Alfredo \& Khefifi Leila (2016), Economic issues and perspectives on innovation in new resistant grapevine varieties in France, Wine Economics and Policy, 5, pp. 73-77.

13. Tang K. et al. (2013), Evaluation of Nonvolatile Flavor Compounds in Vidal Icewine from China, American Journal of Enology and Viticulture, 64(1), pp. 110-117.

14. Hughson A.L. \& Boakes R.A. (2006), The knowing nose: the role of knowledge in wine expertise, Food Quality and Preference, 13(2002), pp. 463-472.

15. Noble A. et al. (1984), Progress Towards a Standardized System of Wine Aroma Terminology Progress Towards a Standardized System of Wine Aroma Terminology, American Journal of Enology and Viticulture, 35(2), pp. 1-4. 